\title{
Avaliação da Eficiência e Retornos de Bancos Brasileiros Após Fusões e Incorporações
}

\author{
Rodrigo Silva Sales ${ }^{1}$ \\ Flávio Leonel de Carvalho
}

\begin{abstract}
Resumo
Após a consolidação do plano real o sistema financeiro nacional passou por profundas mudanças. Destaca-se nesse contexto uma onda de fusões e, principalmente, incorporações de bancos de médio e pequeno porte por parte das maiores instituições financeiras em atividade país. Dado que um dos argumentos favoráveis à incorporação é a possível melhora nos indicadores operacionais e financeiros, este artigo tem como objetivo investigar se as incorporações provocaram melhoras na eficiência dos bancos. Com o emprego de dados disponibilizados pelo Banco Central (BACEN) e Comissão de Valores Mobiliários (CVM) foram listados os 50 maiores bancos brasileiros. Em seguida, e com o emprego do teste $t$ para amostras emparelhadas, analisaram-se os valores médios de variáveis financeiras relacionadas à liquidez, endividamento, margem e rentabilidade das instituições incorporadoras antes e depois do processo de incorporação. Os resultados do presente estudo indicam que a incorporação/fusão foi positiva para o Banco do Brasil e Itaú, no entanto, não se pode afirmar o mesmo para os bancos Bradesco e o Indusval.
\end{abstract}

Palavras-chave: Fusão; Aquisição; Incorporação; Rentabilidade.

\begin{abstract}
After the consolidation of the real plane the national financial system has been undergoing profound changes. It is noteworthy in this context a series of mergers mainly represented by small and medium banks which are the largest financial institutions active in the country. One of the arguments in favor of incorporation is the possible improvement in operational and financial indicators, therefore this article aims to investigate whether the merger caused improvements in the efficiency of banks. The 50 largest Brazilian banks were listed with the employment data provided by the Central Bank (BACEN) and Brazilian Securities Commission (CVM). After that, it was used the $t$ test for paired samples, which was important to analyze the average values of financial variables related to: liquidity, leverage, margin and profitability of developers institutions before and after the merger process. The results of this study indicate that the merger was positive for Brazil Bank and Itaú Bank, however, the same result was not true for banks like Bradesco and Banco Indusval
\end{abstract}

Keywords: Merger; Acquisition; Incorporation; Profitability.

\section{Introdução}

Desde o início da década de 1990, o mercado brasileiro vem passando por profundas mudanças procedentes da evolução tecnológica, da entrada de empresas estrangeiras, da internacionalização de empresas nacionais, das privatizações e, principalmente, procedentes da uma onda de fusões e aquisições. Estas últimas conduziram o Brasil ao processo de abertura financeira e comercial para o mercado internacional.

\footnotetext{
${ }^{1}$ Professor da Universidade Federal de São Carlos. rodsales@gmail.com

${ }^{2}$ Professor Doutor em Engenharia de Produção - Universidade Federal de São Carlos. flcleonel@gmail.com
} 
Essas alterações também geraram uma profunda reestruturação no sistema bancário brasileiro. Esse foi um forte movimento na consolidação do setor no país, tendo como consequência uma redução de bancos e uma maior concentração no mercado financeiro (MARINHO; PAULA; FARIA, 2006).

Esta centralização financeira, motivou inúmeras dúvidas a respeito dos reais benefícios das fusões e aquisições. Calegario, Pessanha e Sáfadi (2012) argumentam que as fusões podem ser consideradas uma intervenção positiva nas métricas da rentabilidade, pois foram capazes de alterar o comportamento das séries de retorno. Além disso, Couto e Silva, Amaral e Bicalho (2003) afirmam que à medida que os bancos aumentam de porte, reduzem seu custo médio podendo gerar economias de escala. Para Elumilade (2010) as aquisições melhoram a competividade e a eficiência das operações bancárias.

No entanto, apesar das fusões e aquisições dos bancos "parecerem" benéficas para o país, apresentando uma maior robustez do mercado financeiro nacional alguns autores contestam tal fato. De acordo com Liargovas (2011) as fusões e aquisições bancárias não apresentam impacto no desempenho dos bancos e, portanto, não agregam riqueza. Conforme Goldner e Araújo (2007) a incorporação no setor financeiro não estaria associada ao aumento dos retornos sobre o ativo (ROA) e patrimônio líquido (ROE). Além disso, Pilloff e Santomero (1996) indicam haver evidências de que, em média, não há nenhum ganho estatisticamente significativo no valor ou desempenho da atividade de incorporação. Outro ponto interessante a ser analisado está relacionado à presença de conflitos de interesses nas negociações. Podem ser apontadas diversas ações realizadas pelos executivos que visam atender seus interesses e lhes trazer benefícios pessoais, ao invés de gerar o incremento da riqueza do acionista ou da sociedade (ASSAF NETO, 2012).

Diante do exposto, o presente estudo tem como objetivo analisar o impacto das incorporações na Liquidez, no Endividamento, na Rentabilidade e na Margem dos bancos brasileiros.

\section{Revisão Teórica}

Na literatura, diversos estudos buscam delinear as motivações das empresas ao se envolverem em processos de fusões e aquisições. Alguns estudos apontam resultados positivos decorrentes do processo de fusão como os trabalhos de Calegario, Pessanha e Sáfadi (2012); Couto e Silva, Amaral e Bicalho (2003); Elumilade (2010); Kloeckner (1993); Silva e Neto (2002) e Silva e Amaral (2013). Outros, por sua vez, não encontraram resultados 
significativos como os estudos de Pessanha, Santos, Alcântra e Calegario (2012); Liargovas (2011) e Dyer, Kale e Singh (2004); ou até mesmo apresentam resultados negativos aos acionistas provenientes da fusão como o apresentado por Goldner e Araújo (2007). As secções a seguir apresentam detalhes desses estudos.

\subsection{Efeitos Positivos}

O trabalho de Kloeckner (1993) afirma que as fusões apresentam maximização da riqueza e ganhos operacionais e, por isso, impacta positivamente no desempenho dos bancos. Em seu artigo Kloeckner apresenta as possíveis causas que levam as incorporações a se fundirem, tais como: busca por economias de escala, com a fusão os custos fixos poderão ser rateados por uma base maior; créditos de impostos de renda, caso a empresa esteja com prejuízos acumulados podem constituir incentivos à medida que outra for lucrativa; e também por fatores pessoais da alta cúpula da empresa, ou seja, quanto maior a empresa, maior a recompensa a seus diretores em termos de salários, benefícios e poder. Com o resultado de sua pesquisa verificou-se que tanto as empresas compradoras quanto os alvos obtêm retornos positivos, mesmo que o verdadeiro fator motivador dos gerentes seja a maximização da própria utilidade.

Em outro trabalho, Pessanha, Calegario e Sáfadi (2012) utilizaram-se de regressão linear simples para identificar o poder de explicação da ocorrência da fusão na rentabilidade e também da metodologia de análise de intervenção para verificar a magnitude e o caráter dos impactos exercidos pela fusão e aquisição. $\mathrm{O}$ resultado obtido foi que as fusões e aquisições podem ser consideradas assertivas para a rentabilidade, sendo que estas foram capazes de alterar o comportamento das séries da rentabilidade de forma positiva.

Para Couto e Silva, Amaral e Bicalho (2003) por meio de análise tabular construíram índices econômico-financeiros que tinham como objetivo demonstrar o ganho em eficiência após a fusão. Dessa forma, detectaram a presença de economias de escala, ou seja, à medida que os bancos aumentam de porte reduzem o seu custo médio.

Silva e Neto (2002) investigaram a ocorrência de economias de escalas no sistema bancário brasileiro entre os anos de 1995 a 1999. Utilizando uma função translog para estimar uma fronteira estocástica de custo, obtiveram estimativas que constatam a ocorrência de economias de escala, independentemente do tamanho do banco e do período.

Já em outro estudo, com mesmo fator economia de escala, Silva e Amaral (2013) utilizando modelos econométricos e análise tabular, também detectaram a presença de 
economias de escala e, de acordo com eles, o aumento de porte dos bancos reduz o seu custo médio das operações.

Para Brigham, Gapenski e Ehrhardt (2001) através da sinergia é possível aumentar o retorno da empresa adquirente. Isso poderá ocorrer pela unificação das operações, pelo ganho através do efeito da tributação, pela compra de ativos abaixo de seu custo de reposição, e por fim, pela diversificação do portfólio que tem como intuito a estabilização dos lucros da empresa e, assim, beneficiar aos seus proprietários.

Para Elumilade (2010) muitas das fusões e/ou incorporações se resumem em uma significativa quantidade de custos operacionais redundantes podendo ser eliminadas por meio da consolidação de atividades. Utilizando um modelo desenvolvido por Klein-Monti (1973) o seu trabalho visou verificar os efeitos da fusão e incorporação sobre a capacidade dos bancos de realizarem as funções primárias de intermediação financeira. O resultado obtido implica que a fusão e a incorporação têm efeito significativo sobre as atividades de empréstimo e de depósito após ocorrerem.

\subsection{Efeitos Negativos}

Para alguns autores o processo de fusão e incorporação no setor bancário causa efeitos negativos ou mesmo nenhum efeito no desempenho do banco. Segundo Godner e Araújo (2007), em sua pesquisa, indicam que a fusão e aquisição no setor financeiro não estaria associada ao aumento de retornos tanto em relação aos ativos quanto do patrimônio líquido. Através de teste de média para duas amostras os autores buscavam confirmar se as fusões e aquisições se correlacionavam com os retornos dos bancos e, por fim, chegaram ao resultado de que as instituições financeiras não estariam aumentando o seu retorno, mas sim sofrendo uma diminuição do retorno mediante riscos de novos entrantes.

Utilizando de uma pesquisa bibliográfica em mais de 200 companhias nos Estados Unidos em 2002, Dyer, Kale e Singh (2004) afirmam que as aquisições destroem ou deixam de gerar valor para a empresa e normalmente criam pouca riqueza para o acionista.

Pessanha, Santos, Alcântra e Calegario (2012), por meio de estudo de evento, buscaram avaliar os retornos para os acionistas após os processos de fusão e incorporação. Os resultados demonstraram que o retorno acumulado não apresentou significância estatística. Diante disso, os resultados dos testes indicam que a fusão e a incorporação não proporcionaram aumento da riqueza dos acionistas das instituições adquirentes.

Em outra pesquisa, efetuada por meio de estudos de eventos sobre os retornos 
derivados dos preços das ações das empresas antes e após incorporação, Liargovas (2011) examinou dados de 1996 a 2008. O resultado obtido apresentou que as fusões e aquisições bancárias não têm impacto na rentabilidade e não criam riquezas para o acionista.

Através de outro estudo, mas com o mesmo resultado de ausência de ganhos, Pilloff e Santomero (1997) efetuaram pesquisa bibliográfica para entender se realmente existe algum tipo de benefício para a empresa após o processo de fusão. No entanto, diante da pesquisa, em média, observaram que não houve nenhum ganho estatisticamente significativo no valor ou desempenho da atividade da incorporação.

Segundo Wood (2005), tais ausências de ganhos podem ser explicadas pelas incorporações repentinas devido ao receio de novos entrantes no mercado. Com a vinda de bancos europeus para o Brasil, as instituições financeiras nacionais passaram a reagir à penetração dos bancos estrangeiros, participando ativamente dos processos de fusão e aquisição, com importantes compras conforme apresentado por Camargo.

Uma característica específica do Brasil foi a reação dos bancos privados nacionais à entrada dos bancos estrangeiros, participando, em um primeiro momento, ativamente do processo de fusões e aquisições e, posteriormente, passando a comandar esse processo, dada a retração dos bancos estrangeiros (CAMARGO,2009,46p).

\section{Metodologia}

\subsection{Amostra e Coleta de Dados}

O presente estudo teve como objetivo analisar o impacto da incorporação/fusão na Liquidez, Rentabilidade, Margem e Endividamento de bancos brasileiros. Para isso, listou-se os cinquenta maiores bancos comerciais e múltiplos brasileiros. Em seguida, por meio de uma pesquisa nas bases de dados do Banco Central do Brasil e da Comissão de Valores Mobiliários identificou-se os bancos que foram incorporados e a data da incorporação. Na sequência, analisou-se as informações financeiras obtidas por meio do Software Economática ${ }^{\circledR}$. Desta forma, os dados incluem informações trimestrais do período de 1990 a 2013. A amostra final dos bancos que fizeram a incorporação, conforme Tabela 1, é composta pelos bancos Banco do Brasil, Itaú, Bradesco, Santander, BTG Pactual e Indusval, os quais representam 66\% de ativos em 2013 da amostra avaliada. Os bancos HSBC, Credit Suisse, Societe Generale e Banco Original foram desconsiderados da pesquisa por apresentarem elementos faltantes na base de dados e por apresentarem o volume de ativos em 2013 de apenas $4 \%$ de ativos da amostra avaliada. 
TABELA 1 - Instituições Adquiridas

\begin{tabular}{|c|c|c|}
\hline Adquirente & $\begin{array}{l}\text { Adquirida } \\
\end{array}$ & Ano \\
\hline Banco do Brasil & Banco do Estado de Santa Catarina - BESC & 2009 \\
\hline Banco do Brasil & Banco Nossa Caixa & 2009 \\
\hline Banco do Brasil & Banco do Estado do Piauí - BEP & 2009 \\
\hline Itaú & BFB S.A. & 1996 \\
\hline Itaú & Banco Banerj S.A. & 1997 \\
\hline Itaú & Banco do Estado de Minas Gerais S.A - Bemge & 1998 \\
\hline Itaú & Banco do Estado do Paraná S.A. - Banestado & 2000 \\
\hline Itaú & Banco do Estado de Goiás S.A. -BEG & 2001 \\
\hline Itaú & Banco BBA Creditanstalt S.A. - BBA & 2003 \\
\hline Bradesco & Banco Itabanco S.A. & 1998 \\
\hline Bradesco & Banco de Crédito Nacional S.A. - BCN & 1998 \\
\hline Bradesco & Banco de Crédito Real S.A. - BCR & 1998 \\
\hline Bradesco & Banco do Estado da Bahia S.A. - Baneb & 1999 \\
\hline Bradesco & Continental Banco S.A. & 1999 \\
\hline Bradesco & Banco BoaVista Interatlântico S.A. & 2000 \\
\hline Bradesco & Banco das Nações S.A. & 2000 \\
\hline Bradesco & Banco do Estado do Amazonas - BEA & 2002 \\
\hline Bradesco & Banco Mercantil de São Paulo S.A. & 2002 \\
\hline Bradesco & Banco Finasa de Investimento S.A. & 2002 \\
\hline Bradesco & Banco Cidade S.A. & 2002 \\
\hline Bradesco & Banco Bilbao Viscaya Argentaria Brasil S.A. - BBV & 2003 \\
\hline Bradesco & Banco do Estado do Maranhão - B.E.M & 2004 \\
\hline Bradesco & Banco do Estado do Ceará - BEC & 2006 \\
\hline Bradesco & Banco BMC & 2007 \\
\hline Bradesco & Banco IBI S.A & 2009 \\
\hline Santander & Banco Geral do Comércio S.A & 1997 \\
\hline Santander & Banco Noroeste S.A & 1998 \\
\hline Santander & Banco Meridional S.A & 2000 \\
\hline Santander & Bozano, Simonsen S.A. DTVM & 2000 \\
\hline Santander & Banco do Estado de São Paulo S.A. - BANESPA & 2000 \\
\hline Santander & Banco ABN Amro Real S.A. & 2008 \\
\hline BTG Pactual & Banco UBS Pactual & 2009 \\
\hline Banco Indusval SA & Banco Intercap S.A. & 2013 \\
\hline
\end{tabular}

Fonte: Elaborado pelo autor

\subsection{Tratamento dos Dados}

O método estatístico utilizado foi o teste de hipóteses para a diferença entre duas médias, com dados emparelhados, a fim de verificar se ocorreu diferença estatisticamente considerável entre as variáveis de margem, rentabilidade, endividamento e liquidez dos bancos estudados em relação ao evento de incorporação ou de aquisição. Ou seja, testou-se os valores médios antes e depois do processo de fusão/incorporação com a finalidade de se verificar se as médias eram estatisticamente diferentes. Modelou-se os dados em uma sequência de f1 até f11, no qual, f1 representa a primeira aquisição do banco em análise, f2 a segunda aquisição e assim sucessivamente até f11. A comparação entre os indicadores de liquidez, endividamento, margem e rentabilidade foi efetuada atribuindo o peso " 0 " até a data de aquisição e "1" pós-aquisição, sendo essa variável a que diferenciará para o cálculo das 
médias. Para a hipótese desenvolvida com base no referencial teórico apresenta:

$$
H_{0}: \mu_{0}=\mu_{1} \text { e } H_{A}: \mu_{0} \neq \mu_{1}
$$

Desta forma, caso a hipótese nula tenha uma média igual ao período anterior a mesma é aceita, caso contrário, será refutada. E, devido à pequena quantidade de dados da pesquisa, a variável estatística que será utilizada na análise é a $t$-test, que conforme descrito por Webster (2006) revela que a distribuição $t$ é usada quando três condições são aceitas, sendo: (1) a amostra é pequena; (2) desvio-padrão ( $\sigma$ ) é desconhecido; (3) a população é normalmente distribuída ou quase. Desta forma, pode-se julgar adequado o uso da distribuição $t$ de Student por apresentar uma pequena amostra (somente seis bancos com dados para um período de 23 anos), o desvio-padrão da população ser desconhecido, $t$ e a população pode ser consideradas normalmente distribuída, pois as variáveis analisadas tratam-se de indicadores financeiros e esses apresentam distribuição próxima a normal.

A fim de melhorar a metodologia de avaliação dos dados obtidos da Economática ${ }^{\circledR}$ os indicadores aqui apresentados foram separados em quatro grupos. O primeiro é sobre a liquidez, que segundo Assaf Neto (2012), representa a capacidade de pagamento de uma empresa. E para a análise, indicará se houve uma melhora no pagamento de suas obrigações após a fusão. O outro grupo está relacionado ao endividamento, que apresenta a composição das fontes passivas de recursos do próprio banco e é o que informa se a instituição utiliza mais de recursos de terceiros ou próprios.

Além disso, serão apresentados também os indicadores relacionados à rentabilidade, pois conforme apresentado por Hirigoyen apud Pimentel et al (2005) a rentabilidade assegura o desenvolvimento da instituição.

Por fim, foram apresentados a margem bruta e líquida dos bancos brasileiros antes e depois do processo de incorporação, para assim analisar se houve uma melhora na atividade fim da instituição financeira, conforme apresentado na Tabela $2 \mathrm{com}$ os indicadores financeiros obtidos na Economática ${ }^{\circledR}$. Para a preparação da base de dados foi utilizada o software Microsoft Excel® versão 2010. Já os testes estatísticos de significância das diferenças das médias foram efetuados com o software Stata $11 \circledR$.

TABELA 2- Quadro resumo das métricas.

\begin{tabular}{|l|l|c|c|l|}
\hline \multicolumn{2}{|c|}{ Métrica } & Sigla* & Fórmula & \multicolumn{1}{c|}{ Interpretação } \\
\hline & Liquidez Corrente & LC & $L C=\frac{\text { AtivoCirculante }}{\text { PassivoCirculante }}$ & $\begin{array}{l}\text { Relação entre as disponibilidades mais as aplicações interfinanceiras de } \\
\text { liquidez e os depósitos. Revela quanto à instituição possui de recursos } \\
\text { disponíveis totais para cobrir seus depósitos. }\end{array}$ \\
\hline & Liquidez Geral & LG & $L G=\frac{A C+R L P}{\text { PassivoTotal }}$ & Mede a liquidez geral da instituição. \\
\hline
\end{tabular}




\begin{tabular}{|c|c|c|c|c|}
\hline 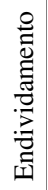 & Grau de Endividamento & GE & $G E=\frac{(A T-P L-P A M)}{\text { AtivoTotal }}$ & $\begin{array}{l}\text { Determina a composição das fontes passíveis da empresa em relação ao } \\
\text { seu Ativo. }\end{array}$ \\
\hline \multirow{2}{*}{ 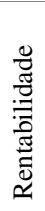 } & Retorno Sobre o Ativo & ROA & $R O A=\frac{(L L+P A M)}{\text { AtivoTotal }}$ & $\begin{array}{l}\text { Determina a rentabilidade da empresa na geração de lucros por meio de } \\
\text { sua estrutura de ativos. }\end{array}$ \\
\hline & Retorno sobre o PL & ROE & $R O E=\frac{(L L+P A M)}{P L-P A M}$ & $\begin{array}{l}\text { Determina o retorno gerado pela empresa através do capital investido } \\
\text { pelos acionistas. }\end{array}$ \\
\hline \multirow{2}{*}{ 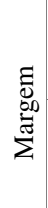 } & Margem Bruta & MB & $M B=\frac{\text { LucroBruto }}{\operatorname{Re} \text { ceitaLiquida }}$ & $\begin{array}{l}\text { Servirá para indicar se houve economia de escala com as fusões e } \\
\text { aquisições. }\end{array}$ \\
\hline & Margem Líquida & ML & $M L=\frac{\text { LucroLíquido }}{\operatorname{Re} \text { ceitaLíquida }}$ & Indica se houve uma melhoria na eficiência operacional e financeira. \\
\hline
\end{tabular}

\subsection{Resultados Obtidos}

\subsubsection{Resultados Obtidos com a Variável Liquidez}

Observa-se na Tabela 3, que a variável liquidez corrente melhorou após o processo de fusão na maioria das situações. O Bradesco, por exemplo, dos onze processos de incorporações apresentou significância em dez casos. Destes dez nota-se uma melhora na média comparada após fusão. Esse resultado pode ser um indicativo de que a fusão/incorporação possibilitou uma melhora na capacidade de pagamento dos bancos e, consequentemente uma redução no risco financeiro dessas instituições. Essa avaliação está coerente com as afirmações de Pimentel (2005) que indica para a manutenção de uma liquidez adequada é mais que o objetivo empresarial, é uma condição para a continuidade do negócio. O mesmo foi apresentado para a Liquidez Geral, havendo assim uma melhora em seu indicador em todos os casos, no entanto, ocorrendo significância em nove das onze incorporações. Já na continuação da tabela, na qual consta os bancos Itaú, Banco do Brasil e Indusval verifica-se uma melhora na liquidez corrente em todos os processos de incorporações, todavia, não havendo significância apenas para o Banco Indusval. Já a Liquidez Geral o mesmo resultado tem-se apresentado para os bancos Itaú e Banco do Brasil, ou seja, uma melhor média desse indicador geral após incorporação, com significância em todos os seus resultados. Porém, novamente, não houve significância para o Banco Indusval.

\subsubsection{Resultados Obtidos com a Variável Endividamento}

Conforme definição de Assaf Neto (2012) os indicadores de endividamento fornecem 
elementos para avaliar o grau de comprometimento financeiro de uma instituição perante os seus credores. Dessa forma, essa variável pode indicar se houve aumento da dívida após a aquisição, e segundo Cruz et al (2006) qualquer aumento da alavancagem financeira por meio de um maior endividamento traduz um maior risco para a instituição. Assim, verifica-se na Tabela 3 que o Banco Bradesco apresentou significância em todas as suas onze incorporações, ou seja, pode ser indicativo que a fusão e/ou incorporação acarretou um aumento de suas dívidas. O mesmo tem-se apresentado no aumento da média do grau de endividamento para o Banco Itaú, o qual em todos os seus períodos houve significância, dessa maneira, podendo ser um indício do aumento das dívidas ocasionadas pelas incorporações. Já para o Banco do Brasil e Indusval não obtiveram significância em suas incorporações, sendo assim, não se pode aferir se houve mudança em sua estrutura de capital devido à incorporação e assim se rejeita a hipótese nula.

\subsubsection{Resultados Obtidos com a Variável Rentabilidade}

Para Pimentel (2005) a rentabilidade pode ser definida como a medida final do grau de êxito econômico obtido por uma instituição em relação ao capital nela investido. Sendo assim, essa variável é de extrema importância para análise, pois, com ela, foi possível determinar se de fato houve aumento no retorno após a incorporação. Para Retorno sobre o Ativo (ROA), o Bradesco em suas primeiras incorporações (f1 e f2) na Tabela 3 obteve significância em suas médias, indicando que a hipótese nula (H0) pode ser refutada. Para as outras próximas sete incorporações o Bradesco não apresentou significâncias de suas médias, ocorrendo novamente apenas nas incorporações $\mathrm{f} 10$ e f11. Isto pode ser um indicativo de que nem todas as incorporações puderam proporcionar um aumento no retorno sobre o ativo da empresa. Considerando a variável Retorno sobre o Patrimônio Líquido (ROE) na Tabela 3, o Bradesco apresentou significância nas nove primeiras aquisições, portanto refutando a H0. Esse resultado é um indicativo de que apesar das incorporações não necessariamente representarem um aumento da eficiência no uso dos ativos elas podem gerar benefícios para o acionista da empresa.

Na continuação da tabela o Banco Itaú apresentou significância apenas na segunda e terceira incorporação (f2 e f3), considerando que houve uma melhora em suas médias comparadas antes da aquisição. Para as outras cinco incorporações não houve significância em seus dados, sendo assim, um indicativo que não são todas as incorporações que podem trazer retorno para a empresa. No entanto, quando se verifica a questão de retorno para o 
acionista o Itaú apresentou significância em todas as suas incorporações. Além disso, a rentabilidade média chegou a ser 75,1\% superior depois da fusão conforme demonstrado na segunda incorporação. Para o Banco do Brasil e Indusval a variável ROA e ROE não apresentaram significâncias, sendo assim, não se pode refutar a hipótese nula, como pode ser observado na Tabele 3.

\subsubsection{Resultados Obtidos com a Margem Operacional e Líquida.}

Conforme os resultados obtidos na Tabela 3 da Margem Bruta (MB) para o Banco Bradesco, nota-se que obteve significância em suas primeiras aquisições, podendo dessa forma refutar a hipótese nula referente à igualdade das médias. Ademais, o mesmo não se pode comentar sobre os períodos seguintes, pois, se verifica que a quarta fusão/incorporação (f4) não obteve significância. Todavia, quando se refere à Margem Líquida (ML) para o Bradesco observa-se que todas as incorporações apresentaram significância em suas variáveis, possivelmente, devido ao melhor controle em suas despesas financeiras. Além disso, quando se compara a média final com a anterior da incorporação se verifica uma melhora em suas margens.

Continuando na tabela 3 observa-se que para o Banco Itaú, Banco do Brasil e Indusval quase em todas as incorporações não se obteve significância em seus dados para a margem bruta, não podendo assim refutar a hipótese nula. Já considerando a margem líquida, verificase uma melhoria de significância em todas as incorporações para o Banco Itaú e Banco do Brasil. Não havendo essa melhoria apenas para o banco Indusval.

Assim, verifica-se que para alguns bancos, como o Banco do Brasil e Itaú, houve um aumento no ganho de escala, provavelmente, ora pela eliminação de setores, processos e rotinas redundantes; ora por aumento na intermediação financeira e, consequentemente, das receitas, sem um aumento proporcional dos gastos operacionais. E para outros bancos como o Bradesco e o Indusval, não apresentou benefício por parte da eficiência operacional. 


\section{Tabela 3 - Apresentação dos testes de diferença de média}

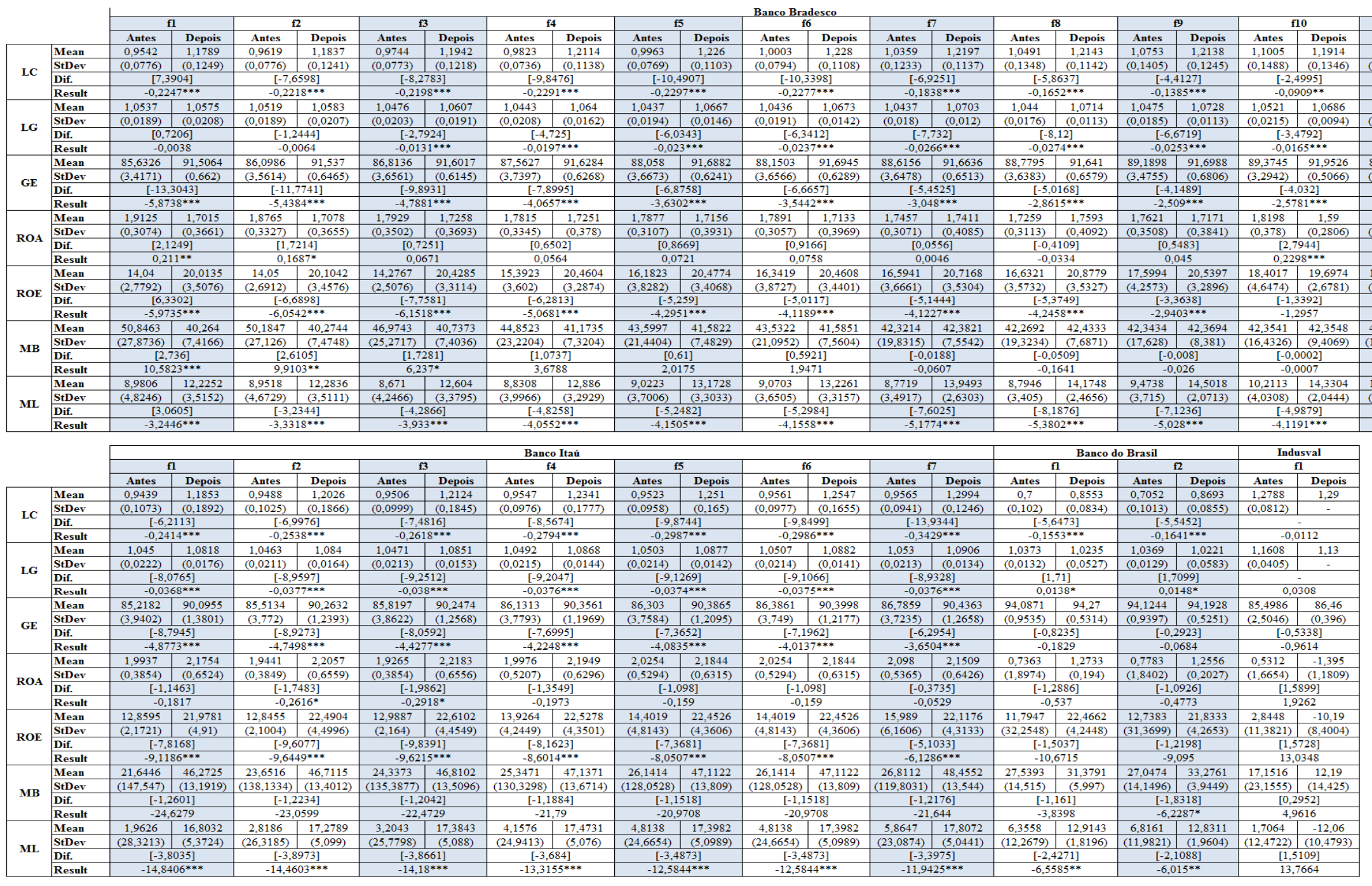

Os valores na tabela referem-se à média, o desvio padrão, diferença e a significância. Os símbolos $\left({ }^{* * *}\right),\left(^{* *}\right)$ e $\left(^{*}\right)$ indicam significância em $1 \%, 5 \%$ e $10 \%$, respectivamente. Fonte: Desenvolvida pelo autor. 


\section{Conclusão}

Esse trabalho teve como propósito verificar se as fusões e incorporações resultaram em um aumento significativo na rentabilidade, endividamento, liquidez e margem após fusão. Foi comparado o desempenho das instituições financeiras com base em dados contábeis, antes e depois da incorporação, no qual, a pesquisa relaciona os bancos com os maiores ativos em 2013. Dos 50 bancos pesquisados, chegou-se a seleção de seis bancos de acordo com a disponibilidade dos dados representativos de 66\% dos ativos em 2013.

Baseando-se na análise do estudo verificou-se haver indícios de que a fusão/incorporação foi positiva para os bancos analisados, possivelmente pela redução dos custos, eliminação de despesas operacionais e exclusão das rotinas redundantes. Tal fato foi confirmado em bancos como o Banco do Brasil e o Itaú, havendo assim uma melhoria nas variáveis de rentabilidade, liquidez e margens (mesmo alguns indicadores não sendo explicados pelo modelo).

No entanto, tal melhoria não foi encontrada em todas as aquisições pesquisadas, bancos como Bradesco e Indusval apresentaram médias inferiores pós-incorporação. A sua rentabilidade, por exemplo, ficou aquém do esperado e a margem bruta, que está atrelada a atividade operacional da empresa, obteve uma variação menor do que estava ocorrendo antes da incorporação.

Por fim, uma sugestão para os próximos trabalhos seria a análise do impacto da percepção do mercado sobre aquisição e incorporação dos bancos envolvidos. Podendo dessa forma, incrementar a pesquisa e fornecer uma visão dos investidores diante a fusão e incorporação de uma instituição financeira.

\section{Referências Bibliográficas}

ASSAF NETO, A. Finanças Corporativas e Valor. 6. ed. São Paulo: Atlas, 2012.

BRIGHAM, E.F.; GAPENSKI, L.C.; EHRHARDT, M. C. Administração Financeira: Teoria e Prática. São Paulo: Atlas, 2001.

CALEGÁRIO, C.L.L.; PESSANHA, G.R.G.; ÁZARA, L.N.; SÁFADI, T. Impactos das estratégias de fusão e aquisição na rentabilidade dos bancos adquirentes: uma aplicação dos modelos de intervenção no setor bancário brasileiro. Revista Administração Mackenzie, v. 13, p. 101-134, 2012.

CAMARGO, P.O. A evolução recente do setor bancário no Brasil. São Paulo: Editora UNESP; São Paulo: Cultura Acadêmica, 322 p. 2009.

CORAZZA, G. “Crise e Reestruturação Bancária no Brasil”. Revista Análise, Porto Alegre, 
v. 12, n. 2, p.21-42, 2001.

CRUZ, A. P. C.; MENDES, R. C.; ESPEJO, M. M. B.; DAMEDA, A. N. Alavancagem Financeira e Rentabilidade: Uma Discussão sobre o Comportamento de Empresas do Sul do Brasil à Luz das Teorias Financeiras, 2006.

MARINHO, A.; PAULA, L.F.; FARIA, J.A. Fusões e Aquisições Bancárias no Brasil: uma Avaliação da Eficiência Técnica e de Escala. Ipea, Rio de Janeiro, 2006.

COUTO E SILVA, A.F.; AMARAL, H.F; BICALHO, J.A.B. Estudo empírico sobre economias de escalas dos bancos no Brasil. Revista de Economia e Administração, v.2, n.1, 46-66p, 2003.

DYER, J.H.; KALE, P.; SINGH, H. When to Ally and When to Acquire. Harvard BusinessReview.

ELUMILADE, D.O. Mergers \& Acquisitions and Efficiency of Financial Intermediation in Nigeria Banks: An Empirical Analysis. International Journal of Business and Management, vol. 5, 2010

FRANCO, M.P.; CAMARGOS, M.A. Fusões e Aquisições no Setor Bancário Brasileiro: Criação de Valor, Rentabilidade, Sinergias Operacionais e Grau de Concentração. ANPAD, 2011 .

GOLDNER, F.; ARAÚJO, C.A.G; BRANDÃO, M.M.; OLIVEIRA, F.R. Estratégia de Fusão e Aquisição Bancária no Brasil: Evidências Empíricas sobre Retornos. Contextus, v. 5, p. 0720, 2007.

KLOECKNER, G.O. Fusões e aquisições: motivos e evidência empírica. Revista de Administração. São Paulo: FEA/USP, v.29, n.1, p.42-58, 1994.

LIARGOVAS, P. The Impact of Mergers and Acquisitions on the Performance of the Greek Banking Sector: An Event Study Approach. International Journal of Business and Management, vol. 3, 2011.

PESSANHA, G.R.G.; SANTOS, T.; ALCÂNTRA, J.N.; CALEGÁRIO, C.L.L. Influências das fusões e aquisições no valor de mercado das instituições bancárias adquirentes: uma aplicação da metodologia de estudo de eventos no período de 1994 a 2009. Semead, 2012.

PIMENTEL, R.C; BRAGA, R; NOVA, S. P. C. N. Interação entre Rentabilidade e Liquidez: Um Estudo Exploratório. Revista de Contabilidade do Mestrado em Ciências Contábeis da UERJ, v.10, n.2, 2005.

PILlOFF, S. J; SANTOMERO, A. M. The Value Effects of Bank Mergers and Acquisitions. Springer link, vol. 3, 1996.

VASCONCELOS, F.C; CALDAS, M. P. ; WOOD J.R.T. Fusões e Aquisições no Brasil: uma

ReFAE - Revista da Faculdade de Administração e Economia, v. 9, n. 1, p. 2-14, 2018 
Análise Crítica do Teatro de Operações. Comportamento Organizacional e Gestão, Lisboa, v. 10, p. 43-58, 2004.

SILVA, T. L.; JORGE NETO, P. M. Economia de escala e eficiência nos bancos brasileiros após o Plano Real. Estudos Econômicos, v. 32, n. 4, p. 577-619, 2002.

WEBSTER, A. L. Estatística Aplicada à Administração e Economia. São Paulo: Editora McGraw-Hill, 2006.

WOOD J, T. (Coord). Gestão empresarial: comportamento organizacional. São Paulo: Atlas, 2005. 